\title{
Desempenho produtivo e nutricional de novilhas de corte em pastejo suplementadas no período da seca e/ou no período de transição seca- águas
}

\author{
Productive and nutritional performance of grazing beef heifers \\ supplemented in the dry season and/or in the dry-rainy transition \\ season
}

\author{
Lívia Vieira de Barros ${ }^{1 *}$; Mário Fonseca Paulino²; \\ Eduardo Henrique Bevitori Kling de Moraes $^{3}$; Edenio Detmann²; \\ Daniel Mageste de Almeida ${ }^{4}$; Leandro Soares Martins ${ }^{4}$; Aline Gomes da Silva ${ }^{4}$; \\ Sidnei Antônio Lopes ${ }^{4}$; David Estaban Conteras Márquez ${ }^{4}$; \\ Javier Enrique Garces Cardenas ${ }^{4}$
}

\begin{abstract}
Resumo
Objetivou-se avaliar o efeito da suplementação com suplemento múltiplo ou mistura mineral durante o período da seca (fase 1) e/ou transição seca-águas (fase 2) sobre as variáveis nutricionais e o desempenho produtivo de novilhas de corte, em pastagem de Uruchloa decumbens. Utilizaram-se 40 novilhas com idade e peso médio iniciais, de 8 meses e $200 \pm 3,74 \mathrm{~kg}$, respectivamente. O delineamento foi inteiramente casualizado com quatro tratamentos e 10 repetições. Na fase 1, dois grupos de animais receberam suplemento múltiplo e os outros dois grupos receberam apenas mistura mineral ad libitum. $\mathrm{Na}$ fase 2 do experimento, dos dois grupos que recebiam suplemento múltiplo, um continuou a receber o suplemento múltiplo e o outro recebeu apenas mistura mineral ad libitum. Já com relação aos dois grupos que receberam apenas mistura mineral na fase 1 , um continuou a receber mistura mineral e o outro passou a receber suplemento múltiplo. Na fase 1, os animais suplementados tiveram maior ganho médio diário (GMD); a suplementação aumentou o consumo ( $\mathrm{kg} / \mathrm{dia})$ de matéria seca (MS), matéria orgânica (MO), $\mathrm{PB}$, carboidratos não fibrosos (CNF), matéria seca digerida (MSD) e nutrientes digestíveis totais (NDT) e melhorou a digestibilidade de todos os constituintes da dieta $(\mathrm{P}<0,10)$, com exceção da fibra em detergente neutro ( $\mathrm{FDNcp}$ ) e do extrato etéreo (EE) $(\mathrm{P}>0,10)$. A suplementação na transição seca-águas (fase 2) aumentou o consumo ( $\mathrm{kg} / \mathrm{dia}$ ) de MS, matéria seca de forragem (MSF), $\mathrm{MO}$, matéria orgânica de forragem (MOF), $\mathrm{PB}, \mathrm{EE}, \mathrm{MSD}$, fibra em detergente neutro digerida (FDND) e fibra em detergente neutro indigestível. Houve efeito de interação sobre a suplementação na seca e na transição seca-águas sobre o GMD, consumo de CNF, sobre os coeficientes de digestibilidade da MS, MO, PB, FDNcp e sobre o teor de NDT. Recomenda-se o uso de suplementos múltiplos para novilhas de corte sob pastejo em fase de recria durante o período da seca e durante o período de transição secaáguas. A suplementação durante a seca melhora o desempenho dos animais suplementados durante a transição seca-águas.
\end{abstract}

Palavras-chave: Forragem, ganho de peso, novilhas, suplementação

\footnotetext{
${ }^{1}$ Prof ${ }^{a}$, Universidade do Estado de Mato Grosso, UNEMAT, Cáceres, MT. E-mail: barrosufv@yahoo.com.br

2 Profs., Universidade Federal de Viçosa, UFV, Viçosa, MG. E-mail: mpaulino@ufv.br; detmann@ufv.br

${ }^{3}$ Prof., Universidade Federal do Mato Grosso, UFMT, Sinop, MT. E-mail: edukling@ufmt.br

${ }^{4}$ Discentes, UFV, Viçosa, MG. E-mail: danielmagestedealmeida@yahoo.com.br; leandro_martins@yahoo.com.br; alinegomesdasilva@rocketmail.com; sidneyufv@hotmail.com; davidstebas@hotmail.com; jojavier1@hotmail.com

* Autor para correspondência
} 


\begin{abstract}
The objective of this work was to evaluate the effect of supplementation with multiple supplement or mineral mixture in the dry season (phase 1) and/or dry-rainy transition season (phase 2) on nutritional variables and productive performance of beef cattle in Uruchloa decumbens pasture. 40 heifers at initial age and average weight of 8 months and $200 \pm 3.74 \mathrm{~kg}$, respectively in a complete random design with four treatments and 10 replicates, were used. In the phase 1, two groups of animals were fed multiple supplement and the other two groups were fed only mineral mixture ad libitum. In the second phase of the experiment, the two groups that received multiple supplements, one continued to receive multiple supplements and the other was receiving only mineral. Regarding the two groups fed only mineral mixture in the phase 1 , one continued receiving mineral mixture in phase 2 and the other receiving supplement in phase 2 . In the phase 1 , supplemented animals presented higher daily average gain (DAG), the supplementation increased intake in $\mathrm{kg} /$ day of dry matter (DM), organic matter (OM), $\mathrm{CP}$, non fibrous carbohydrates (NFC), digested dry matter (DDM), and total digestible nutrients (TDN) and it improved digestibility of all dietary constituents $(\mathrm{P}<0.10)$, except those of neutral detergent fiber (NDFap) and ether extract $(\mathrm{EE})(\mathrm{P}<0.10)$. The supplementation in the dry-rainy transition season (phase 2) increased intake in $\mathrm{kg} /$ day of $\mathrm{DM}$, forage dry matter (FDM), OM, forage organic matter (FOM), CP, EE, DDM, digested neutral detergent fiber (DNDF) and indigestible neutral detergent fiber. There was an interaction effect on supplementation in the dry season and in the dry-rainy transition season on the DAG, NFC intake, on the coefficients of DM, OM, CP, NDFap and on the content of TDN. It is recommended the use of multiple supplements for grazing beef heifers in the growth phase in the dry season and in the rainy-dry transition period. Supplementation in the dry season improves performance of supplemented animals in the rainy-dry transition season.
\end{abstract}

Key words: Forage, heifers, supplementation, weight gain

\section{Introdução}

Em sistemas de produção de animais com estação de monta definida (novembro - janeiro), a fase de recria geralmente, ocorre durante a estação seca e durante a transição seca/águas. A duração da fase de recria é variável e influencia diretamente na rentabilidade do sistema produtivo.

Durante o período seco a diminuição na qualidade da forragem em função do aumento na parede celular e lignificação (VAN SOEST, 1994), influencia negativamente a digestibilidade e o consumo voluntário (LAZZARINI et al., 2009; SAMPAIO et al., 2010). Observa-se ainda que os teores proteicos destas gramíneas dificilmente atingem o valor de $7 \%$ de $\mathrm{PB}$, relatado por Lazzarini et al. (2009) como mínimo para que não haja comprometimento do crescimento microbiano ruminal e, consequentemente, para que ocorra utilização eficiente dos carboidratos fibrosos da forragem basal.

Já no final do período seco e início da estação das chuvas (transição seca-águas), observase predominância de aparecimento de brotos na pastagem. Estes brotos, segundo Poppi e McLennan (1995) são constituídos de proteína de alta degradabilidade, elevando o risco de perdas na forma de amônia. Por outro lado, à medida que as plantas vão amadurecendo, ocorre mobilização deste nitrogênio presente sob forma de proteínas solúveis para formas insolúveis associadas à parede celular (PAULINO et al., 2004).

A bovinocultura de corte brasileira, que tem o pasto como a base da alimentação dos bovinos, deve buscar a ampliação da capacidade de produção. Práticas adequadas de manejo devem ser utilizadas nas diferentes épocas do ano, visando propiciar aos animais, ganho de peso adequado, mesmo durante as épocas em que a forragem disponível apresentar menor qualidade e quantidade. Uma das estratégias para otimização da eficiência produtiva da bovinocultura de corte é a utilização de suplementos múltiplos para os animais criados em pastagens, durante as várias fases do sistema 
produtivo de bovinos de corte.

Devido às interações existentes entre forragem, suplemento e fase de produção nas diferentes épocas do ano, grandes variações no consumo e aproveitamento do pasto e na produção animal podem ocorrer. Muito ainda se questiona sobre a viabilidade e o nível ideal de suplementação concentrada a ser utilizado em cada fase de vida dos animais e época do ano, e mesmo a resposta produtiva possível de ser alcançada. Questiona-se também sobre o efeito que a suplementação concentrada em determinada fase pode ter sobre a suplementação nas fases seguintes do sistema produtivo. Assim, objetivou-se avaliar os efeitos da suplementação de novilhas em pastejo com suplemento múltiplo (protéico, energético e mineral) ou mistura mineral durante o período da seca e/ou transição seca-águas sobre o desempenho produtivo e as variáveis nutricionais.

\section{Material e Métodos}

O experimento foi conduzido nas dependências do Setor de Bovinocultura de Corte da Universidade Federal de Viçosa (2045' S e 42 ${ }^{\circ} 52^{\prime}$ W), localizado no município de Viçosa-MG. A área experimental está localizada em uma região montanhosa com $670 \mathrm{~m}$ de altitude e apresenta precipitação média anual de $1300 \mathrm{~mm}$. O experimento teve duração de 168 dias divididos em duas fases com 84 dias cada. A fase 1, referente ao período da seca, foi conduzida entre os meses de julho a setembro de 2010. A fase 2, referente ao período de transição seca-águas, foi conduzida foi entre os meses de outubro e dezembro de 2010.

Foram utilizadas 40 novilhas com, no mínimo, $50 \%$ de sangue Nelore, com idade e pesos médios iniciais, de 8 meses e $200 \pm 3,74 \mathrm{~kg}$, respectivamente.

Foi destinada aos animais uma área experimental com 10 hectares, sendo esta constituída por quatro piquetes de 2,5 ha, formados com a gramínea Uruchloa decumbens (Capim-braquiária), providos de bebedouros e cochos cobertos e com acesso pelos dois lados.

O delineamento experimental foi o inteiramente casualizado, com quatro tratamentos e dez repetições por tratamento.

$\mathrm{Na}$ primeira fase, durante o período seco, dois grupos receberam suplemento múltiplo e os outros dois grupos receberam apenas mistura mineral ad libitum. Na segunda fase do experimento, durante o período de transição seca-águas, dos dois grupos que recebiam suplemento múltiplo, um continuou a receber suplemento múltiplo e o outro recebeu apenas mistura mineral ad libitum. Já com relação aos dois grupos que receberam apenas mistura mineral na fase 1 , um continuou a receber mistura mineral e o outro passou a receber suplemento múltiplo. A fórmula do suplemento múltiplo utilizado nas duas fases encontra-se na Tabela 1. Nas duas fases, os animais suplementados receberam 1 $\mathrm{kg}$ de suplemento por dia. Os suplementos foram fornecidos diariamente, às $10 \mathrm{~h} 00$, em comedouro conjunto, com dois metros de comprimento, para permitir o acesso simultâneo dos animais. A água foi disponibilizada ad libitum para todos os animais durante todo o período experimental.

Tabela 1. Composição (em $\mathrm{g} / \mathrm{kg})$ do suplemento, com base na matéria natural.

\begin{tabular}{lc}
\hline \multicolumn{1}{c}{ Ingredientes } & Suplemento múltiplo \\
\hline Mistura mineral $^{1}$ & 60 \\
Sorgo & 210 \\
Milho & 210 \\
Farelo de soja & 500 \\
Uréia/SA & 20 \\
\hline
\end{tabular}

${ }^{1}$ Composição percentual: fosfato bicálcico, 50,00; cloreto de sódio, 47,775; sulfato de zinco, 1,40; sulfato de cobre, 0,70 ; sulfato de cobalto, 0,05; iodato de potássio, 0,05 e selenito de sódio 0,025 .

Fonte: Elaboração dos autores.

Ao início de cada fase do experimento, todos os animais foram submetidos ao controle de ecto e endoparasitas e durante o período experimental, 
quando necessário.

Os animais foram pesados no início do experimento após jejum de 14 horas e em seguida foram aleatoriamente distribuídos em quatro lotes, que formaram os diferentes tratamentos. A cada sete dias os animais foram rotacionados entre os piquetes, visando o controle de possíveis efeitos de piquetes sobre os tratamentos (disponibilidade de pasto, localização da aguada e cocho, relevo, sombreamento e outros).

O ganho médio diário de peso (GMD) das novilhas em cada fase experimental foi estimado pela diferença entre o peso corporal final e o inicial, dividido pelo número de dias experimentais em cada fase (84 dias).

A amostragem para avaliação qualitativa do pasto consumido pelos animais foi realizada via simulação manual do pastejo a cada 14 dias. Essa amostra foi pesada e levada imediatamente à estufa com circulação forçada de ar a $60^{\circ} \mathrm{C}$ por 72 horas e moída em moinho de facas (1 mm).

No décimo quarto dia de cada período experimental foi realizada coleta do pasto para quantificação da massa de MS e de MS potencialmente digestível (MSpd), através do corte rente ao solo de quatro áreas delimitadas por um quadrado metálico de $0,5 \times 0,5 \mathrm{~m}$, selecionados aleatoriamente em cada piquete experimental. Essa amostra também foi pesada e levada imediatamente à estufa com circulação forçada de ar a $60^{\circ} \mathrm{C}$ por 72 horas.

A MSpd foi estimada segundo Paulino, Detmann e Valadares Filho (2008):

$$
\mathrm{MSpd}=0,98 \times(100-\mathrm{FDNcp})+(\mathrm{FDNcp}-\mathrm{FDNi})
$$

Para a avaliação das características nutricionais, a partir do $35^{\circ}$ dia do período de cada fase experimental foi realizado um ensaio com duração de nove dias. Utilizou-se o método de três indicadores. Para estimar a excreção fecal, foi fornecido aos animais o indicador externo óxido crômico $\left(\mathrm{Cr}_{2} \mathrm{O}_{3}\right)$ (DETMANN et al., 2001), acondicionado em cartuchos de papel, correspondente a $15 \mathrm{~g}$ por animal/dia, aplicado com auxílio de um aplicador metálico diretamente no esôfago, sempre às 10h00. Para estimar o consumo individual de suplemento foi utilizado o dióxido de titânio $\left(\mathrm{TiO}_{2}\right)$ (TITGEMEYER et al., 2001) fornecido via suplemento na proporção de $10 \mathrm{~g}$ de indicador $/ \mathrm{kg}$ de suplemento. Para estimar o consumo de MS total e MS de pasto foi utilizado como indicador interno a FDNi (DETMANN, et al., 2001).

Dos nove dias do ensaio, seis foram destinados à adaptação ao $\mathrm{Cr}_{2} \mathrm{O}_{3}$ e ao $\mathrm{TiO}_{2}$. Nos últimos três dias foram realizadas coletas de fezes em horários diferenciados, às $15 \mathrm{~h} 00,11 \mathrm{~h} 00$ e às $7 \mathrm{~h} 00$, respectivamente. As amostras de fezes foram coletadas imediatamente após a defecação ou diretamente no reto dos animais, em quantidades aproximadas de $200 \mathrm{~g}$, sendo identificadas por animal e secas em estufa com circulação forçada de ar $\left(60^{\circ} \mathrm{C} / 72\right.$ horas $)$ e após a secagem, moídas em moinho de facas $(1 \mathrm{~mm})$.

No quinto dia do ensaio foi realizada uma simulação manual de pastejo, em cada piquete separadamente, sendo estas amostras usadas para a estimação do consumo e dos coeficientes de digestibilidade.

No último dia do ensaio de digestibilidade de cada fase foram obtidas amostras "spot" de urina, em micção espontânea, e de sangue, via punção da veia jugular, realizadas aproximadamente quatro horas após o fornecimento do suplemento. Após a coleta, as amostras de urina foram diluídas com 40 $\mathrm{mL}$ de $\mathrm{H}_{2} \mathrm{SO}_{4}(0,036 \mathrm{~N})$ e congeladas a $-20^{\circ} \mathrm{C}$ para posterior avaliação dos teores de creatinina, uréia e derivados de purina. As amostras de sangue foram coletadas ao final do período de coleta de urina utilizando-se de tubos de vácuo com ativador de coágulo e gel separador (BD Vacuntainer ${ }^{\circledR}$, SST II Advance). O sangue foi imediatamente centrifugado a $2700 \times$ g por 15 minutos sendo o soro armazenado $\left(-20^{\circ} \mathrm{C}\right)$.

Nas amostras de forragem obtidas via simulação 
manual do pastejo e dos concentrados foram quantificados os teores de matéria seca(MS); matéria mineral (MM); proteína bruta (PB), extrato etéreo (EE) e lignina, segundo Silva e Queiroz (2002). $\mathrm{O}$ teor de fibra em detergente neutro (FDNcp), foi avaliado segundo Mertens (2002), utilizandose $\alpha$-amilase termoestável e omitindo-se o uso de sulfito de sódio. Foram realizadas correções para proteína e cinzas na FDN, quantificou-se o teor de nitrogênio insolúvel em detergente neutro (NIDN) e o teor de fibra em detergente ácido (FDA) seguindo as recomendações de Van Soest e Robertson (1985), com correções para proteína e cinzas; fibra em detergente neutro indigestível (FDNi), de acordo com Valente et al. (2011b), obtida após a incubação em sacos (F57 Ankom $^{\circledR}$ ) in situ por 288 horas. Nas amostras de forragem destinadas ao cálculo da massa de MS e MSpd foram quantificados os teores de MS; FDNcp e FDNi, conforme descrito anteriormente.

Os carboidratos não fibrosos dos suplementos foram estimados segundo recomendações de Hall e Akinyode (2000), utilizando-se a seguinte equação:

$$
\begin{aligned}
& C N F c p=100-[(\% P B-\% P B U+\% \text { de uréia })+ \\
& \% F D N c p+\% E E+\% \text { de cinzas })
\end{aligned}
$$

onde: $\mathrm{PBU}=\mathrm{PB}$ no suplemento advinda da uréia

A composição do suplemento e da forragem é apresentada na Tabela 2 .

Foi elaborada uma amostra composta de fezes com base no peso seco ao ar, por animal, dos três dias de coleta, as quais foram armazenadas em potes plásticos, devidamente identificadas e posteriormente analisadas quanto aos teores de cromo, por espectrofotometria de absorção atômica (WILLIANS; DAVID; IISMA, 1962) e dióxido de titânio por colorimetria (TITGEMEYER et al., 2001). Avaliaram-se também os teores de MS; PB; EE; FDNcp; FDNi e MM, conforme descrito anteriormente.

A excreção de matéria seca fecal foi estimada utilizando-se o indicador óxido crômico, sendo estimada com base na razão entre a quantidade do indicador fornecido e sua concentração nas fezes.

A estimativa do consumo individual de suplemento foi obtida através da seguinte equação:

$$
\text { CISup }=((E F x C I F i) / I F G) x \operatorname{SupFG}
$$

em que: CISup = consumo individual de suplemento ( $\mathrm{kg} / \mathrm{dia}) ; \mathrm{EF}$ = excreção fecal em kg/ dia; CIFi = concentração do indicador nas fezes do animal $(\mathrm{kg} / \mathrm{kg}) ; \mathrm{IFG}=$ indicador presente no suplemento fornecido ao grupo $(\mathrm{kg} / \mathrm{dia}) ; \mathrm{SupFG}=$ quantidade de suplemento fornecida ao grupo de animais (kg/dia).

A estimação do consumo voluntário de matéria seca foi realizada empregando-se como indicador interno a FDN indigestível, conforme a equação:

$\mathrm{CMS}(\mathrm{kg} / \mathrm{dia})=\{[(\mathrm{EFxCIF})-\mathrm{IS}] / \mathrm{CIFO}\}+\mathrm{CMSS}$

em que: CIF = concentração do indicador nas fezes $(\mathrm{kg} / \mathrm{kg})$; CIFO = concentração do indicador na forragem $(\mathrm{kg} / \mathrm{kg}) ; \mathrm{CMSS}=$ consumo de matéria seca de suplemento (kg/dia); EF = excreção fecal ( $\mathrm{kg} / \mathrm{dia})$; e IS = consumo de indicador a partir do suplemento $(\mathrm{kg})$. 
Tabela 2. Composição química do suplemento e da Uruchloa decumbens.

\begin{tabular}{|c|c|c|c|c|c|}
\hline \multirow{2}{*}{ Item $^{1}$} & \multirow{2}{*}{$\begin{array}{l}\text { Suplemento } \\
\text { Múltiplo }\end{array}$} & \multicolumn{2}{|c|}{ Fase 1 (Seca) } & \multicolumn{2}{|c|}{ Fase 2 (Transição seca-águas) } \\
\hline & & Forragem $^{2}$ & Forragem $^{3}$ & Forragem $^{2}$ & Forragem $^{3}$ \\
\hline $\begin{array}{l}\text { Matéria seca }(\mathrm{g} / \mathrm{kg} \\
\text { de } \mathrm{MN})\end{array}$ & 918,40 & $349,0 \pm 2,28$ & $325,1 \pm 0,84$ & $287,0 \pm 5,70$ & $228,8 \pm 0,88$ \\
\hline $\begin{array}{l}\text { Matéria orgânica } \\
\text { (g/kg de MS) }\end{array}$ & 905,1 & $916,4 \pm 0,09$ & $913,0 \pm 0,44$ & $929,6 \pm 0,48$ & $918,2 \pm 0,25$ \\
\hline $\begin{array}{l}\text { Proteína bruta } \\
\text { (g/kg de MS) }\end{array}$ & 325,7 & $54,7 \pm 0,53$ & $41,1 \pm 0,18$ & $110,6 \pm 1,23$ & $140,2 \pm 0,09$ \\
\hline $\begin{array}{l}\text { NIDN }(g / k g \text { de } \\
\text { NT) }\end{array}$ & 105,1 & $102,7 \pm 1,10$ & $151,4 \pm 2,87$ & $317,2 \pm 0,32$ & $372,9 \pm 1,41$ \\
\hline $\begin{array}{l}\text { Extrato etéreo } \\
\text { (g/kg de } \mathrm{MS})\end{array}$ & 15,9 & $11,7 \pm 0,07$ & $12,3 \pm 0,10$ & $13,9 \pm 0,11$ & $20,1 \pm 0,05$ \\
\hline $\begin{array}{l}\text { FDNcp }(\mathrm{g} / \mathrm{kg} \mathrm{de} \\
\text { MS) }\end{array}$ & 137,4 & $602,2 \pm 1,04$ & $663,2 \pm 1,22$ & $586,5 \pm 4,53$ & $535,4 \pm 1,26$ \\
\hline $\begin{array}{l}\text { Carboidratos não } \\
\text { fibrosos }(\mathrm{g} / \mathrm{kg} \text { de } \\
\mathrm{MS})\end{array}$ & 426,1 & $247,8 \pm 0,43$ & $196,4 \pm 0,48$ & $218,6 \pm 1,89$ & $222,2 \pm 1,09$ \\
\hline $\begin{array}{l}\text { FDAcp }(\mathrm{g} / \mathrm{kg} \text { de } \\
\mathrm{MS})\end{array}$ & 42,1 & $276,6 \pm 0,76$ & $305,0 \pm 1,16$ & $278,4 \pm 1,84$ & $245,8 \pm 0,15$ \\
\hline $\begin{array}{l}\text { FDNi (g/kg de } \\
\text { MS) }\end{array}$ & 11,9 & $249,1 \pm 0,01$ & $246,5 \pm 0,86$ & $279,0 \pm 0,45$ & $200,3 \pm 0,76$ \\
\hline $\begin{array}{l}\text { Lignina }(\mathrm{g} / \mathrm{kg} \text { de } \\
\mathrm{MS})\end{array}$ & 18,2 & $54,8 \pm 0,56$ & $57,8 \pm 0,08$ & $46,1 \pm 0,44$ & $49,3 \pm 0,33$ \\
\hline
\end{tabular}

${ }^{1} \mathrm{MN}$ - matéria natural; MS - matéria seca; NT - nitrogênio total; NIDN - nitrogênio insolúvel em detergente neutro; FDNcp fibra em detergente neutro corrigida para cinzas e proteína; FDAcp - fibra em detergente ácido corrigida para cinzas e proteína; FDNi - fibra em detergente neutro indigestível. ${ }^{2}$ Média das amostras obtidas por simulação manual do pastejo durante todo o período experimental. ${ }^{3}$ Média das amostras obtidas durante o ensaio para avaliação das características nutricionais.

Fonte: Elaboração dos autores.

Para estimar os teores urinários de uréia foram utilizados o método enzimático-colorimétrico (InVitro ${ }^{\circledR}$, Uréia Liquicolor), para ácido úrico o método enzimático-colorimétrico com fator clareante de lípedes (InVitro ${ }^{\circledR}$, Uric Acid Liquicolor), e os teores de creatinina foram estimados pelo método de Jaffé modificado (InVitro ${ }^{\circledR}$, Creatinina). O cálculo do volume urinário diário foi feito empregando-se a relação entre a excreção diária de creatinina (EC), adotando-se como referência a equação proposta por Silva et al. (2012), e a sua concentração nas amostras "spot":

$\operatorname{ECU}(\mathrm{g} / \mathrm{dia})=0,0345 \times \mathrm{PCJ}^{0,9491}$

em que: $\mathrm{PCJ}=$ peso corporal em jejum.

As análises de alantoína foram feitas pelo método colorimétrico (CHEN; GOMES, 1992). A excreção total de derivados de purinas foi calculada pela soma das quantidades de alantoína e ácido úrico excretados na urina.

As purinas absorvidas (PA, mmol/dia) foram calculadas a partir da excreção de derivados de purinas (DP, mmol/dia), por intermédio da equação:

$$
P A=\frac{D P-0,301 \times P C^{0,75}}{0,80}
$$

em que: 0,80 é a recuperação de purinas absorvidas como derivados de purinas e $0,301 \mathrm{PC}^{0,75}$, a contribuição endógena para a excreção de purinas (BARBOSA et al., 2011).

A síntese ruminal de compostos nitrogenados (g Nmic/dia) foi calculada em função das purinas 
absorvidas (PA, mmol/dia), utilizando-se a equação descrita por Barbosa et al. (2011):

$$
N_{\text {mic }}=\frac{70 \times P A}{0,93 \times 0,137 \times 1000}
$$

em que: 70 é o conteúdo de $\mathrm{N}$ de purinas (mg $\mathrm{N} / \mathrm{mol}$ ); 0,137, a relação $\mathrm{N}$ purinas: $\mathrm{N}$ total nas bactérias; e 0,93, a digestibilidade das purinas bacterianas.

A eficiência microbiana foi expressa em g PB microbiana/kg de nutrientes digestíveis totais ( $\mathrm{g}$ PBmic/kg NDT).

Utilizou-se o PROC MIXED do SAS (Statistical Analysis System, versão 9.2) em todas as análises estatísticas. Adotando-se $\alpha=0,10$. Foi realizada a análise das fases em separado. Na fase 1 o delineamento foi inteiramente casualizado com 2 tratamentos e na fase 2 o delineamento foi inteiramente casualizado com quatro tratamentos em fatorial $2 \times 2$ (2 tratamentos prévios e 2 tratamentos durante a fase 2 do experimento). Utilizou-se o peso corporal inicial como co-variável.

\section{Resultados e Discussão}

O consumo voluntário de forragem pelo animal e o desempenho em pastejo está diretamente relacionado à quantidade e a qualidade da forragem disponível. Quanto maior a possibilidade do animal selecionar materiais com maiores proporções de fibra em detergente neutro potencialmente digestível (FDNpd), menores entraves sobre o consumo podem ser observados, sendo o consumo um dos principais determinantes do desempenho de animais em pastejo. Segundo Paulino, Detmann e Valadares Filho (2008) a matéria seca potencialmente digestível (MSpd) constitui medida integradora dos aspectos quantitativos e qualitativos do pasto, o que permite maior precisão na avaliação real da capacidade de suporte e desempenho animal na área utilizada. Para otimizar o desempenho produtivo há necessidade de massa de MSpd que permita ao animal optar por material de melhor valor nutritivo.

Na fase 1 (seca) as massas médias de MS e MSpd foram de 4194,9 e 2640,9 kg/ha, respectivamente. $\mathrm{O}$ teor médio de $\mathrm{PB}$ na forragem durante esta fase foi de $54,7 \mathrm{~g}$ de $\mathrm{PB} / \mathrm{kg}$ de MS. Na fase 2 (transição seca-águas) a massa de MS e MSpd foi de 4765,7 e 2929,1 kg/ha, respectivamente, com teor médio de $\mathrm{PB}$ de $110 \mathrm{~g}$ de $\mathrm{PB} / \mathrm{kg}$ de $\mathrm{MS}$.

Paulino et al. (2004) preconizaram oferta de MSpd de pasto ao redor de 40 a $50 \mathrm{~g} / \mathrm{kg}$ de PC dos animais para um desempenho satisfatório dos animais em regime de pastejo. No presente trabalho a massa média de MSpd foi de 111,8 e $116,4 \mathrm{~g} / \mathrm{kg}$ de PC, nas fase 1 e 2 , respectivamente, que pode ser considerada como não restritiva em relação ao desempenho animal. No entanto, o teor médio de $\mathrm{PB}$ na forragem durante a fase 1 do período experimental foi de 54,7 g de $\mathrm{PB} / \mathrm{kg}$ de $\mathrm{MS}$, valor este que se encontra abaixo de $100 \mathrm{~g}$ de $\mathrm{PB} / \mathrm{kg}$ de MS sugerido por Sampaio et al. (2009) como o nível ótimo para utilização dos substratos energéticos da forragem e o consumo.

Nestas condições, os níveis limitantes de PB da forragem basal comprometem o crescimento das bactérias que utilizam como substrato os carboidratos fibrosos da forragem basal (LAZZARINI et al., 2009), reduzindo a utilização da FDNpd pelos microrganismos e consequentemente, o desempenho animal (PAULINO; DETMANN; VALADARES FILHO, 2008).

O ganho médio diário de peso (GMD) (Tabela 3 ) para os animais suplementados com suplementos múltiplos na fase 1 foi maior $(\mathrm{P}<0,10)$ do que para os animais suplementados apenas com mistura mineral. 
Tabela 3. Médias, desvio padrão e indicativos de significância de peso corporal final e ganho médio diário de animais suplementados com suplementos múltiplos e animais suplementados apenas com mistura mineral durante a seca

\begin{tabular}{lcccc}
\hline \multirow{2}{*}{ Item } & \multicolumn{2}{c}{ Estratégia Fase 1 (Seca) } & \multirow{2}{*}{ Desvio Padrão } & \multirow{2}{*}{ Valor - P } \\
\cline { 2 - 3 } & Suplementadas & Não suplementadas & & \\
Peso corporal inicial $(\mathrm{kg})$ & 199,9 & 201,6 & & \\
Peso corporal final $(\mathrm{kg})$ & 227,4 & 214,8 & 6,721 & $<0,0001$ \\
Ganho médio diário $(\mathrm{kg})$ & 0,318 & 0,167 & 0,079 & $<0,0001$ \\
\hline
\end{tabular}

Fonte: Elaboração dos autores.

O GMD para os animais suplementados na fase 1 foi maior do que o GMD dos animais não suplementados $(\mathrm{P}<0,10)$. No entanto, mesmo para os animais suplementados, o GMD foi baixo, provavelmente pelo baixo teor de PB e NDT na forragem. Desta forma, a forragem foi deficiente qualitativamente, o que prejudicou a ocorrência de ganhos mais expressivos. Isso pode ser confirmado comparando com os dados de Valente et al. (2011a) em que novilhas em recria em pastagem com disponibilidade de $2560 \mathrm{~kg}$ de $\mathrm{MSpd} / \mathrm{ha}$ e com teor de PB igual a 66,4 g de PB/ $\mathrm{kg}$ de MS no período seco do ano, consumiram $1,214 \mathrm{~kg}$ de suplemento por dia com $400 \mathrm{~g} \mathrm{~PB} /$ $\mathrm{kg}$ e tiveram GMD de $307 \mathrm{~g}$. Mesmo com elevado consumo de suplemento, a baixa qualidade da forragem disponível limita o desempenho animal. As exigências em PB e NDT de novilhas com $200 \mathrm{~kg}$ de PC para GMD igual a 500 gramas são $521,7 \mathrm{~g}$ e $2,72 \mathrm{~kg}$, respectivamente (BR-CORTE, 2010). Na fase 1 deste estudo, as novilhas suplementadas tiveram consumo médio diário de 456 gramas de PB e 2,3 kg de NDT. Nas novilhas não suplementadas o consumo diário de $\mathrm{PB}$ foi $197 \mathrm{~g}$ e o consumo de NDT foi igual 1,67 kg. Os baixos consumos de NDT e PB explicam o baixo GMD observado na fase 1 . No entanto, apesar do baixo GMD observado, a suplementação na fase 1 promoveu um incremento de $90,4 \%$ no GMD das novilhas.

Observaram-se diferenças nos consumos (Tabela 4) de MS, MO, PB, CNF, MSD e NDT (kg/dia), entre os animais suplementados com suplementos múltiplos e suplementados apenas com mistura mineral $(\mathrm{P}<0,10)$ na fase 1 . Em todos os casos a suplementação aumentou o consumo. Os consumos de MS e MO em $\mathrm{g} / \mathrm{kg}$ de peso corporal foram maiores para os animais que receberam suplementos múltiplos.

$\mathrm{O}$ aumento no consumo em $\mathrm{kg} / \mathrm{dia}$ observado para as variáveis $\mathrm{MS}, \mathrm{MO}, \mathrm{PB}, \mathrm{CNF}, \mathrm{MSD}$ e NDT na fase 1 foi devido ao consumo de matéria seca de suplemento pois, não houve diferença no consumo de matéria seca de forragem entre os animais suplementados e não suplementados. 
Tabela 4. Médias, desvio padrão e indicativos de significância dos consumos de componentes da dieta.

\begin{tabular}{|c|c|c|c|c|}
\hline \multirow[b]{2}{*}{ Item } & \multicolumn{2}{|c|}{ Estratégias Fase 1 (Seca) } & \multirow[b]{2}{*}{$\begin{array}{l}\text { Desvio } \\
\text { padrão }\end{array}$} & \multirow[b]{2}{*}{ Valor - P } \\
\hline & $\begin{array}{l}\text { Suplemento } \\
\text { múltiplo }\end{array}$ & $\begin{array}{c}\text { Suplemento } \\
\text { mineral }\end{array}$ & & \\
\hline \multicolumn{5}{|l|}{$\mathrm{kg} / \mathrm{dia}$} \\
\hline Matéria seca & 4,11 & 3,43 & 0,667 & 0,0029 \\
\hline Matéria seca de forragem & 3,28 & 3,43 & 0,663 & 0,4710 \\
\hline Matéria orgânica & 3,82 & 3,16 & 0,608 & 0,0017 \\
\hline Matéria orgânica de forragem & 3,02 & 3,16 & 0,608 & 0,4924 \\
\hline Proteína bruta & 0,45 & 0,19 & 0,038 & $<0,0001$ \\
\hline Extrato etéreo & 0,08 & 0,07 & 0,013 & 0,0355 \\
\hline $\mathrm{FDNcp}^{1}$ & 2,22 & 2,18 & 0,424 & 0,7290 \\
\hline Carboidratos não fibrosos & 1,06 & 0,70 & 0,134 & $<0,0001$ \\
\hline Matéria seca digerida & 2,19 & 1,62 & 0,319 & $<0,0001$ \\
\hline Fibra em detergente neutro digerida & 1,39 & 1,35 & 0,253 & 0,6223 \\
\hline Nutrientes digestíveis totais & 2,33 & 1,67 & 0,323 & $<0,0001$ \\
\hline Fibra em detergente neutro indigestível & 0,84 & 0,80 & 0,163 & 0,4497 \\
\hline \multicolumn{5}{|l|}{$\mathrm{g} / \mathrm{kg}$ de peso corporal } \\
\hline Matéria seca & 18,16 & 15,77 & 0,608 & 0,0194 \\
\hline Matéria seca de forragem & 14,51 & 15,77 & 2,941 & 0,1858 \\
\hline Matéria orgânica & 16,89 & 14,48 & 2,811 & 0,0110 \\
\hline Matéria orgânica de forragem & 13,36 & 14,48 & 2,701 & 0,2020 \\
\hline $\mathrm{FDNcp}^{1}$ & 9,83 & 10,02 & 1,859 & 0,7527 \\
\hline Fibra em detergente neutro indigestível & 3,72 & 3,66 & 0,734 & 0,8038 \\
\hline
\end{tabular}

${ }^{1}$ FDNcp: Fibra em detergente neutro corrigida para cinzas e proteínas.

Fonte: Elaboração dos autores.

A suplementação múltipla na fase 1 aumentou da dieta (Tabela 5), exceto da FDNcp e do EE $(\mathrm{P}<0,10)$ a digestibilidade de todos os constituintes $\quad(\mathrm{P}>0,10)$.

Tabela 5. Médias, desvio padrão e indicativos de significância dos coeficientes de digestibilidade $(\mathrm{kg} / \mathrm{kg}) \mathrm{de}$ componentes da dieta e teor de nutrientes digestíveis totais.

\begin{tabular}{lcccc}
\hline \multirow{2}{*}{ Item } & \multicolumn{2}{c}{ Estratégias Fase 1 (Seca) } & \multirow{2}{*}{ Desvio Padrão } & \multirow{2}{*}{ Valor - P } \\
\cline { 2 - 3 } & Suplemento múltiplo & Suplemento mineral & & \\
\hline Matéria Seca & 0,5365 & 0,4726 & 0,0272 & $<0,0001$ \\
Matéria orgânica & 0,5904 & 0,5236 & 0,0273 & $<0,0001$ \\
Proteína bruta & 0,5896 & 0,4220 & 0,0561 & $<0,0001$ \\
Extrato etéreo & 0,3009 & 0,2502 & 0,1074 & 0,1489 \\
Fibra em detergente neutro & 0,6289 & 0,6228 & 0,0263 & 0,4772 \\
Carboidratos não fibrosos & 0,5578 & 0,2737 & 0,0568 & $<0,0001$ \\
Nutrientes digestíveis totais & 0,5723 & 0,4874 & 0,0263 & $<0,0001$ \\
\hline
\end{tabular}

Fonte: Elaboração dos autores. 
O aumento no coeficiente de digestibilidade de todos os constituintes da dieta na fase 1 , exceto da FDNcp e do EE, pode ser devido à presença de compostos mais facilmente digeríveis na dieta dos animais que receberam suplemento múltiplo.

O coeficiente de digestibilidade aparente de $\mathrm{CNF}$ é diretamente proporcional ao consumo destes componentes (VAN SOEST, 1994). Desta forma, justifica-se a ampliação da digestibilidade dos CNF com a suplementação durante a seca, visto que o fornecimento de suplemento aumentou o consumo de CNF. Os baixos valores observados para a digestibilidade aparente total do EE foram provavelmente devido ao baixo teor de EE na dieta.

A mensuração da massa ingerida efetivamente digerida permite integrar os efeitos da suplementação sobre o consumo e digestibilidade; neste estudo observou-se efeito da suplementação sobre o consumo de MS e sobre a digestibilidade da MS (Tabela 5), o que elevou o consumo de MSD nos animais suplementados com suplementos múltiplos. A maior digestibilidade da MS nos animais suplementados, pode ser devida em parte, à maior ingestão de compostos nutricionais de fácil digestão, ao invés do aumento da digestibilidade do pasto, visto que não houve alteração da digestibilidade total da FDNcp $(\mathrm{P}>0,10)$ em resposta ao consumo de suplemento.

O fornecimento adicional de proteína via suplemento múltiplo otimiza o desempenho dos animais. O fornecimento dos suplementos foi capaz de elevar o teor de PB na dieta total dos animais experimentais para valores próximos a $111 \mathrm{~g}$ de $\mathrm{PB} /$ $\mathrm{kg}$ de MS ou seja, para valor acima de $100 \mathrm{~g}$ de $\mathrm{PB} / \mathrm{kg}$ de MS sugerido por Sampaio et al. (2009) como o nível que otimiza o consumo e a utilização dos substratos energéticos da forragem. Desta forma, esperava-se aumento no consumo de FDNcp e FDND com o fornecimento de suplemento, contudo, isso não ocorreu, provavelmente pelo fato de que aproximadamente $37 \%$ do nitrogênio estava lentamente disponível para o animal, ou seja, estava na forma de NIDN (Tabela 2).

Os incrementos causados no teor de NDT da dieta com a suplementação múltipla (Tabela 5) parecem refletir a ampliação dos coeficientes de digestibilidade da PB e CNF, não havendo aumento significativo na extração de energia a partir da FDNcp considerando-se que tenha elevado o consumo de NDT, sem, contudo afetar o consumo de FDNcp digerida (Tabela 4).

O consumo médio de FDNcp observado foi de $9,92 \mathrm{~g} / \mathrm{kg}$ de PC, inferior ao observado por outros pesquisadores durante o período da seca (MORAES et al., 2009; FIGUEIRAS et al., 2010; MORAES et al., 2010), indicando que o consumo de pasto pode não ter sido otimizado.

$\mathrm{O}$ valor de consumo médio de matéria seca de forragem (MSF) de 14,51 g/kg PC foi inferior a $20,84 \mathrm{~g} / \mathrm{kg}$ PC (COUTO et al., 2010) e 20,66 g/ $\mathrm{kg}$ PC (VALENTE et al., 2011a) encontrados em trabalhos anteriores, pois, a baixa qualidade da forragem não permitiu a maximização do consumo, tornando os efeitos da suplementação múltipla sobre o consumo menos evidente. Não houve efeito do tipo de suplementação na fase 1 sobre a síntese de $\mathrm{N}$ microbiano (Tabela 6). Os animais que receberam suplementos múltiplos apresentaram menor eficiência de síntese de proteína bruta microbiana. 
Tabela 6. Médias, desvio padrão e indicativos de significância da eficiência microbiana e nitrogênio uréico sérico.

\begin{tabular}{|c|c|c|c|c|}
\hline \multirow[b]{2}{*}{ Item } & \multicolumn{2}{|c|}{ Estratégias Fase 1 (Seca) } & \multirow[b]{2}{*}{$\begin{array}{l}\text { Desvio } \\
\text { Padrão }\end{array}$} & \multirow[b]{2}{*}{ Valor - P } \\
\hline & $\begin{array}{l}\text { Suplemento } \\
\text { múltiplo }\end{array}$ & $\begin{array}{c}\text { Suplemento } \\
\text { Mineral }\end{array}$ & & \\
\hline $\mathrm{N}$ microbiano (g/dia) & 32,83 & 29,77 & 10,4240 & 0,3023 \\
\hline Eficiência Microbiana (g PB/kg de NDT) & 88,83 & 115,31 & 43,3410 & 0,0186 \\
\hline Nitrogênio uréico no soro $(\mathrm{mg} / \mathrm{dL})$ & 21,46 & 7,37 & 4,3897 & $<0,0001$ \\
\hline
\end{tabular}

Fonte: Elaboração dos autores.

O GMD (Tabela 7) dos animais que receberam suplemento múltiplo na fase 2 foi maior $(\mathrm{P}<0,10)$ do que o dos animais que receberam apenas mistura mineral na fase 2 e houve efeito de interação da suplementação na fase 1 e 2 sobre o GMD.

Tabela 7. Médias, desvio padrão e indicativos de significância de peso corporal final e ganho médio diário em animais submetidos a diferentes estratégias durante a fase 2 (transição seca-águas).

\begin{tabular}{|c|c|c|c|c|c|c|c|c|}
\hline \multirow{3}{*}{ Item } & \multicolumn{4}{|c|}{$\begin{array}{c}\text { Estratégias Fase } 2^{1} \\
\text { (Transição seca -águas) }\end{array}$} & \multirow{3}{*}{$\begin{array}{l}\text { Desvio } \\
\text { Padrão }\end{array}$} & \multirow{2}{*}{\multicolumn{3}{|c|}{ Valor- $\mathrm{P}^{2}$}} \\
\hline & \multicolumn{2}{|c|}{ Ss } & \multicolumn{2}{|c|}{$\mathrm{Sc}$} & & & & \\
\hline & Ts & $\mathrm{Tc}$ & Ts & $\mathrm{Tc}$ & & $\mathrm{S}$ & $\mathrm{T}$ & SxT \\
\hline Peso corporal inicial $(\mathrm{kg})$ & 213,0 & 218,2 & 226,3 & 225,2 & & & & \\
\hline Peso corporal final (kg) & 220,4 & 228,3 & 221,6 & 243,6 & 25,29 & 0,3093 & 0,0698 & 0,3840 \\
\hline Ganho médio diário $(\mathrm{kg})$ & 0,088 & 0,120 & $-0,056$ & 0,219 & 0,2827 & 0,3772 & $<0,0001$ & $<0,0001$ \\
\hline
\end{tabular}

${ }^{1}$ Ss: Sem suplementação na seca. Sc: Com suplementação na seca. Ts: Sem suplementação na transição seca/águas. Tc: Com suplementação na transição seca/águas.

${ }^{2} \mathrm{~S}$ : Efeito na suplementação na seca. T: Efeito da suplementação na transição seca-águas. SxT: Efeito da interação da suplementação na seca com a suplementação na transição seca-águas.

Fonte: Elaboração dos autores.

A suplementação múltipla na fase 2 aumentou $(\mathrm{P}<0,10)$ o consumo (kg/dia) de MS, MSF, MO, MOF, PB, EE, MSD, FDND e FDNi (Tabela 8).
Houve efeito de interação da suplementação na seca e na transição seca-águas sobre o consumo de CNF. 
Tabela 8. Médias, desvio padrão e indicativos de significância de consumos de componentes da dieta e de peso corporal dos animais submetidos a diferentes estratégias de suplementação durante a fase 2 (transição seca-águas).

\begin{tabular}{|c|c|c|c|c|c|c|c|c|}
\hline \multirow{3}{*}{ Item $^{1}$} & \multicolumn{4}{|c|}{ Estratégia Fase $2^{2}$ (Transição seca-águas) } & \multirow{3}{*}{$\begin{array}{l}\text { Desvio } \\
\text { Padrão }\end{array}$} & \multirow{2}{*}{\multicolumn{3}{|c|}{ Valor- $\mathrm{P}^{3}$}} \\
\hline & \multicolumn{2}{|c|}{ Ss } & \multicolumn{2}{|c|}{$\mathrm{Sc}$} & & & & \\
\hline & Ts & Tc & Ts & $\mathrm{Tc}$ & & $\mathrm{S}$ & $\mathrm{T}$ & SxT \\
\hline \multicolumn{9}{|c|}{$\mathrm{kg} / \mathrm{dia}$} \\
\hline Matéria seca & 4,26 & 5,28 & 4,23 & 6,02 & 0,96 & 0,2569 & $<0,0001$ & 0,2145 \\
\hline Matéria seca de forragem & 4,26 & 4,52 & 4,23 & 5,29 & 0,96 & 0,2378 & 0,0357 & 0,1978 \\
\hline Matéria orgânica & 3,89 & 4,91 & 3,86 & 5,57 & 0,88 & 0,2678 & $<0,0001$ & 0,2230 \\
\hline Matéria orgânica de forragem & 3,89 & 4,18 & 3,86 & 4,87 & 0,88 & 0,2460 & 0,0256 & 0,2040 \\
\hline Proteína bruta & 0,59 & 0,87 & 0,59 & 0,99 & 0,13 & 0,1849 & $<0,0001$ & 0,1841 \\
\hline Extrato etéreo & 0,08 & 0,10 & 0,08 & 0,11 & 0,01 & 0,4321 & 0,0016 & 0,9935 \\
\hline FDNcp & 2,13 & 2,63 & 2,25 & 3,01 & 0,51 & 0,1477 & 0,0005 & 0,4542 \\
\hline Carboidratos não fibrosos & 1,08 & 1,35 & 0,92 & 1,52 & 0,21 & 0,9001 & $<0,0001$ & 0,0212 \\
\hline Matéria seca digerida & 2,36 & 3,17 & 2,41 & 3,39 & 0,58 & 0,4551 & $<0,0001$ & 0,6548 \\
\hline $\begin{array}{l}\text { Fibra em detergente neutro } \\
\text { digerida }\end{array}$ & 1,25 & 1,70 & 1,38 & 1,92 & 0,33 & 0,0965 & $<0,0001$ & 0,6499 \\
\hline Nutrientes digestíveis totais & 2,37 & 3,27 & 2,39 & 3,57 & 0,58 & 0,3942 & $<0,0001$ & 0,4787 \\
\hline $\begin{array}{l}\text { Fibra em detergente neutro } \\
\text { indigestível }\end{array}$ & 0,83 & 0,91 & 0,84 & 1,07 & 0,19 & 0,2290 & 0,0249 & 0,1944 \\
\hline \multicolumn{9}{|c|}{$\mathrm{g} / \mathrm{kg}$ de peso corporal } \\
\hline Matéria seca & 19,92 & 23,69 & 18,56 & 25,06 & 4,37 & 0,9971 & 0,0007 & 0,3308 \\
\hline Matéria seca de forragem & 19,92 & 20,19 & 18,56 & 22,04 & 3,96 & 0,8875 & 0,1917 & 0,2310 \\
\hline Matéria orgânica & 18,31 & 21,91 & 16,97 & 23,21 & 4,05 & 0,9886 & 0,0005 & 0,3092 \\
\hline FDNcp & 10,04 & 11,75 & 9,91 & 12,51 & 2,32 & 0,6826 & 0,0058 & 0,5496 \\
\hline $\begin{array}{l}\text { Fibra em detergente neutro } \\
\text { indigestível }\end{array}$ & 4,01 & 4,08 & 3,71 & 4,45 & 0,86 & 0,8932 & 0,1497 & 0,2359 \\
\hline
\end{tabular}

${ }^{1}$ FDNcp: Fibra em detergente neutro corrigida para proteínas e cinzas. ${ }^{2}$ Ss: Sem suplementação na seca. Sc: Com suplementação na seca. Ts: Sem suplementação na transição seca/águas. Tc: Com suplementação na transição seca/águas. ${ }^{3} \mathrm{~S}$ : Efeito na suplementação na seca. T: Efeito da suplementação na transição seca-águas. SxT: Efeito da interação da suplementação na seca com a suplementação na transição seca-águas.

Fonte: Elaboração dos autores.

A suplementação na fase 2 aumentou $(\mathrm{P}<0,10)$ o efeito de interação da suplementação na fase 1 e 2 coeficiente de digestibilidade da MS, MO, FDNcp sobre a digestibilidade da MS, MO, PB, FDNcp e e PB e aumentou o teor de NDT (Tabela 9). Houve sobre o teor de NDT. 
Tabela 9. Médias, desvio padrão e indicativos de significância para os coeficientes de digestibilidade $(\mathrm{kg} / \mathrm{kg})$ de componentes da dieta e teor de nutrientes digestíveis totais.

\begin{tabular}{|c|c|c|c|c|c|c|c|c|}
\hline \multirow{3}{*}{ Item } & \multicolumn{4}{|c|}{ 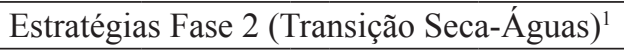 } & \multirow{3}{*}{$\begin{array}{l}\text { Desvio } \\
\text { Padrão }\end{array}$} & \multirow{2}{*}{\multicolumn{3}{|c|}{ Valor- $\mathrm{P}^{2}$}} \\
\hline & \multicolumn{2}{|c|}{ Ss } & \multicolumn{2}{|c|}{$\mathrm{Sc}$} & & & & \\
\hline & Ts & $\mathrm{Tc}$ & Ts & $\mathrm{Tc}$ & & $\mathrm{S}$ & $\mathrm{T}$ & SxT \\
\hline Matéria seca & 0,5517 & 0,6004 & 0,5669 & 0,5652 & 0,0330 & 0,3423 & 0,0308 & 0,0210 \\
\hline Matéria orgânica & 0,5971 & 0,6493 & 0,608 & 0,6241 & 0,0288 & 0,4290 & 0,0005 & 0,0496 \\
\hline Proteína Bruta & 0,5897 & 0,6879 & 0,6312 & 0,6072 & 0,0499 & 0,2225 & 0,0244 & 0,0004 \\
\hline Extrato Etéreo & 0,3436 & 0,2654 & 0,2702 & 0,3092 & 0,1464 & 0,7512 & 0,6744 & 0,2137 \\
\hline $\mathrm{FDNcp}^{3}$ & 0,5841 & 0,6462 & 0,6093 & 0,6427 & 0,0228 & 0,1421 & $<0,0001$ & 0,0554 \\
\hline Carboidratos não fibrosos & 0,6465 & 0,6754 & 0,6228 & 0,6352 & 0,0470 & 0,0385 & 0,1742 & 0,5816 \\
\hline Nutrientes digestíveis totais & 0,5543 & 0,6215 & 0,5629 & 0,5947 & 0,0911 & 0,3262 & $<0,0001$ & 0,0597 \\
\hline
\end{tabular}

${ }^{1}$ Ss: Sem suplementação na seca. Sc: Com suplementação na seca. Ts: Sem suplementação na transição seca/águas. Tc: Com suplementação na transição seca/águas ${ }^{2} \mathrm{~S}$ : Efeito na suplementação na seca. T: Efeito da suplementação na transição seca-águas. SxT: Efeito da interação da suplementação na seca com a suplementação na transição seca-águas. ${ }^{3}$ Fibra em detergente neutro corrigida para cinzas e proteínas.

Fonte: Elaboração dos autores.

A excreção fecal de $\mathrm{N}$ foi afetada $(\mathrm{P}<0,10)$ pela suplementação na fase 2 e houve ação interativa da suplementação na fase 1 e na fase 2. Em adição, a excreção urinária de $\mathrm{N}$ foi ampliada $(\mathrm{P}<0,10)$ pela suplementação na fase 2 , mas não foi houve efeito de interação (Tabela 10). As estimativas de balanço aparente de compostos nitrogenados (BN) somente foram incrementadas $(\mathrm{P}<0,10)$ pela suplementação múltipla durante a fase 2 (Tabela 10).

As estimativas de nitrogênio uréico no soro (NUS) foram incrementadas $(\mathrm{P}<0,10)$ pela suplementação na fase 2 e não houve efeito de interação para esta variável.

A produção absoluta de compostos nitrogenados no rúmen $(\mathrm{NMIC})$ não foi afetada $(\mathrm{P}>0,10)$ pela suplementação na fase 1 ou na fase 2 ou sua interação. Contudo, a produção relativa destes compostos em relação ao consumo de nitrogênio (NMICR) foi reduzida $(\mathrm{P}<0,10)$ pela suplementação na fase 2 . A eficiência de síntese microbiana no rúmen (EFIM), foi reduzida pela suplementação na fase 2 .

As estimativas de NUS tem sido empregadas para se diagnosticar a adequação da utilização de compostos nitrogenados no rúmen em função da disponibilidade de matéria orgânica degradável (SAMPAIO et al., 2009). Valadares et al. (1997) sugeriram que os níveis de N-uréia plasmática entre 13,52 e 15,15 mg/dL correspondem à máxima eficiência microbiana em novilhos alimentados com $62,5 \%$ de NDT. O NDT da dieta dos animais que receberam suplemento múltiplo do presente trabalho foi em torno de $57,0 \%$, indicando que pode ter havido uma falta de compostos energéticos no rúmen para a maximização da EFIM, justificando os altos valores de NUS que foram encontrados para os animais suplementados na fase 1 (Tabela $6)$. 
Tabela 10. Médias, desvio padrão e indicativos de significância de balanço de nitrogênio $(\mathrm{N})$, eficiência microbiana e nitrogênio uréico sérico.

\begin{tabular}{|c|c|c|c|c|c|c|c|c|}
\hline \multirow{3}{*}{ Item } & \multicolumn{4}{|c|}{ Estratégias Fase 2} & \multirow{3}{*}{$\begin{array}{l}\text { Desvio } \\
\text { Padrão }\end{array}$} & \multirow{2}{*}{\multicolumn{3}{|c|}{ Valor- P }} \\
\hline & \multicolumn{2}{|c|}{ Ss } & \multicolumn{2}{|c|}{$\mathrm{Sc}$} & & & & \\
\hline & Ts & $\mathrm{Tc}$ & Ts & $\mathrm{Tc}$ & & $\mathrm{S}$ & $\mathrm{T}$ & SxT \\
\hline Nitrogênio microbiano & 62,71 & 65,50 & 57,93 & 64,83 & 13,9226 & 0,4701 & 0,2250 & 0,6054 \\
\hline Eficiência Microbiana & 170,65 & 127,82 & 158,70 & 115,69 & 45,2809 & 0,3346 & 0,0011 & 0,9812 \\
\hline Nitrogênio uréico no soro & 16,63 & 25,29 & 16,27 & 25,96 & 3,0844 & 0,8738 & $<0,0001$ & 0,6050 \\
\hline
\end{tabular}

${ }^{1}$ Ss: Sem suplementação na seca. Sc: Com suplementação na seca. Ts: Sem suplementação na transição seca/águas. Tc: Com suplementação na transição seca/águas ${ }^{2} \mathrm{~S}$ : Efeito na suplementação na seca. T: Efeito da suplementação na transição seca-águas. SxT: Efeito da interação da suplementação na seca com a suplementação na transição seca-águas.

Fonte: Elaboração dos autores.

O menor valor de eficiência microbiana observada para os animais suplementados na fase 1 pode ser devido ao maior consumo de NDT, visto que a EFIM é uma relação entre a síntese de PB microbiana e o consumo de NDT. Esta observação pode ser confirmada pelo fato dos animais suplementados na fase 1 terem tido maior consumo de NDT e pelo fato de que não houve diferença em relação a síntese de nitrogênio microbiano entre os animais suplementados e não suplementados na fase 1.

O desdobramento do efeito de interação (Tabela 11) da suplementação na fase 1 e fase 2 sobre o GMD, consumo de CNF, digestibilidade da MS, MO, PB, FDNcp, sobre o teor de NDT e sobre a excreção fecal de nitrogênio, está apresentado na Tabela 11.

Os animais suplementados na fase 2 apresentaram maior GMD (Tabela 7). Tal resultado pode ser atribuído ao maior consumo de PB (Tabela 8) pelos animais suplementados, o que apresentou efeito benéfico sobre o ambiente ruminal, incrementando o crescimento microbiano sobre os carboidratos fibrosos, propiciando assim melhor uso da forragem consumida, com maior consumo de MSD e FDND e consequentemente melhor ganho de peso. Apesar do maior GMD observado nos animais suplementados, o GMD na fase 2 foi baixo. Na transição seca-águas, o processo de crescimento da forragem se inicia de forma rápida e se caracteriza por ampla emissão de folhas novas. A relação folha:colmo e o teor de proteína se elevam rapidamente. Devido ao alto teor de proteína solúvel nas folhas recémemitidas, a suplementação neste período pode causar diarréias nos animais (DETMANN; PAULINO; VALADARES FILHO, 2010). Fato este, que foi observado neste trabalho e que pode ter comprometido o ganho de peso dos animais. Houve efeito de interação da suplementação na fase 1 e 2 para o GMD (Tabela 7), as interações serão discutidas posteriormente. 
Tabela 11. Desdobramento do efeito de interação da suplementação na seca e na transição seca-águas.

\begin{tabular}{|c|c|c|}
\hline \multirow{2}{*}{ Fase 2 (Transição Seca/Águas) ${ }^{1}$} & \multicolumn{2}{|c|}{ Fase $1(\text { Seca })^{1}$} \\
\hline & Suplemento Mineral & Suplemento Múltiplo \\
\hline & \multicolumn{2}{|c|}{ Ganho médio diário (g/dia) } \\
\hline Suplemento mineral & $88 \mathrm{Aa}$ & $-56 \mathrm{Bb}$ \\
\hline \multirow[t]{2}{*}{ Suplemento múltiplo } & $120 \mathrm{Ab}$ & 219Aa \\
\hline & \multicolumn{2}{|c|}{ Consumo de carboidratos não fibrosos (kg/dia) } \\
\hline Suplemento mineral & $1,082 \mathrm{Aa}$ & $0,928 \mathrm{Aa}$ \\
\hline \multirow[t]{2}{*}{ Suplemento múltiplo } & $1,353 \mathrm{Ba}$ & $1,525 \mathrm{Bb}$ \\
\hline & \multicolumn{2}{|c|}{ Digestibilidade da matéria seca $(\mathrm{kg} / \mathrm{kg})$} \\
\hline Suplemento mineral & $0,5517 \mathrm{Aa}$ & $0,5669 \mathrm{Ba}$ \\
\hline \multirow[t]{2}{*}{ Suplemento múltiplo } & $0,6004 \mathrm{Ba}$ & $0,5652 \mathrm{Bb}$ \\
\hline & \multicolumn{2}{|c|}{ Digestibilidade da matéria orgânica (kg/kg) } \\
\hline Suplemento mineral & $0,5971 \mathrm{Aa}$ & $0,6084 \mathrm{Aa}$ \\
\hline \multirow[t]{2}{*}{ Suplemento múltiplo } & $0,6493 \mathrm{Ba}$ & $0,6241 \mathrm{Ab}$ \\
\hline & \multicolumn{2}{|c|}{ Digestibilidade da proteína bruta $(\mathrm{kg} / \mathrm{kg})$} \\
\hline Suplemento mineral & $0,5897 \mathrm{Aa}$ & $0,6312 \mathrm{Ab}$ \\
\hline \multirow[t]{2}{*}{ Suplemento múltiplo } & $0,6879 \mathrm{Ba}$ & $0,6072 \mathrm{Ab}$ \\
\hline & \multicolumn{2}{|c|}{ Digestibilidade da fibra em detergente neutro $(\mathrm{kg} / \mathrm{kg})$} \\
\hline Suplemento mineral & $0,5841 \mathrm{Aa}$ & $0,6093 \mathrm{Ab}$ \\
\hline \multirow[t]{2}{*}{ Suplemento múltiplo } & $0,6462 \mathrm{Ba}$ & $0,6427 \mathrm{Ba}$ \\
\hline & \multicolumn{2}{|c|}{ Nutrientes digestíveis totais $(\mathrm{kg} / \mathrm{kg})$} \\
\hline Suplemento mineral & $0,5543 \mathrm{Aa}$ & $0,5629 \mathrm{Aa}$ \\
\hline Suplemento múltiplo & $0,6215 \mathrm{Ba}$ & $0,5947 \mathrm{Bb}$ \\
\hline
\end{tabular}

${ }^{1}$ Médias na coluna, seguidas por letras maiúsculas diferentes, ou na linha, seguidas por letras minúsculas diferentes, são diferentes pelo teste $\mathrm{F}(\mathrm{P}<0,10)$.

Fonte: Elaboração dos autores.

A forragem coletada durante a fase 2 do período experimental apresentou teor médio de PB de $110 \mathrm{~g}$ de $\mathrm{PB} / \mathrm{kg}$ de MS (Tabela 2) estando acima do valor $100 \mathrm{~g}$ de $\mathrm{PB} / \mathrm{kg}$ de MS citado por Sampaio et al. (2009), como nível que otimiza a utilização de substratos energéticos da forragem. No entanto, quase $40 \%$ do nitrogênio presente na forragem estava lentamente disponível para o animal, ou seja, na forma de nitrogênio insolúvel em detergente neutro (NIDN) (Tabela 2), o que justifica o uso de suplementos protéicos para que a degradação da FDNcp seja potencializada e também aumente a taxa de passagem do resíduo indigestível, com consequente aumento no consumo de matéria seca de pasto e melhora no desempenho animal. Este fato pode ser comprovado pelo desempenho superior dos animais suplementados em relação aos animais não suplementados (Tabela 7) e pelo maior consumo de matéria seca de forragem e de FDNcp nos animais suplementados na fase 2 .

A suplementação na fase 2 aumentou $(\mathrm{P}<0,10)$ a digestibilidade aparente total da MS, MO e PB. A maior digestibilidade dos componentes da dieta para os animais suplementados, pode ser devido em parte, a maior ingestão de componentes nutricionais de fácil digestão, e ao aumento da digestibilidade do pasto, visto que houve aumento da digestibilidade da FDNcp $(\mathrm{P}<0,10)$ em resposta ao consumo de suplemento na fase 2 . Houve efeito de interação da suplementação nas fases 1 e 2 sobre os coeficientes de digestibilidade dos componentes da dieta, exceto para EE e CNF.

A avaliação do efeito da interação sobre as 
variáveis estudadas permitiu verificar que houve efeito de interação para as seguintes variáveis estudadas: GMD, consumo de CNF, coeficiente de digestibilidade aparente total da MS, MO, PB; coeficiente de digestibilidade da fibra em detergente neutro, teor de NDT e excreção fecal de nitrogênio. Em relação ao GMD, os animais que não foram suplementados na fase 1 não apresentaram diferença no ganho médio diário na fase 2 . No entanto, em relação aos animais que foram suplementados na fase 1 , os que deixaram de ser suplementados na fase 2 apresentaram perda de peso. Os animais não suplementados na fase 2 e que foram suplementadas na fase 1 apresentaram menor GMD do que os animais não suplementados nas duas fases. Em relação aos animais que foram suplementados na fase 2, os que também foram suplementados durante a fase 1 apresentaram maior GMD, demonstrando a importância da suplementação na seca e na transição seca-águas para melhorar o desempenho dos animais criados em pastagens.

$\mathrm{O}$ consumo de CNF foi maior nos animais suplementados com suplementos múltiplos na fase 2 sendo que entre os suplementados com suplementos múltiplos o consumo foi maior nos animais que também receberam suplemento múltiplo na fase 1. A digestibilidade da MS na fase 2 foi maior em animais que não foram suplementados na fase 1 e suplementados na fase 2 . A digestibilidade da PB, MO e o teor de nutrientes digestíveis totais apresentou comportamento similar à digestibilidade da MS. Os animais que receberam suplementos múltiplos na fase 1 e receberam apenas mistura mineral na fase 2 apresentaram menor digestibilidade da FDNcp.

Considerando que a digestibilidade é determinada pelas características intrínsecas do alimento e pela capacidade de atuação dos sistemas enzimáticos microbiano e animal (DETMANN; PAULINO; VALADARES FILHO, 2008), os efeitos interativos observados podem estar relacionados com alterações nos sistemas enzimáticos dos animais e com as alterações observadas na forragem durante as duas fases. Sendo assim, os animais que receberam suplementos múltiplos na fase $1 \mathrm{e}$ deixaram de receber suplemento múltiplo na fase 2 tiveram provavelmente redução no crescimento dos microrganismos fibrolíticos, o que fez com que estes animais tivessem menor digestibilidade da FDNcp, que é a principal fonte de energia para os animais criados a pasto, e consequentemente menor GMD.

\section{Conclusões}

A suplementação múltipla durante o período da seca melhora o consumo e as variáveis nutricionais, o que melhora o desempenho produtivo dos animais suplementados com suplementos múltiplos durante a transição seca-águas. Recomenda-se o uso de suplementos múltiplos para novilhas de corte sob pastejo em fase de recria durante o período da seca e durante o período de transição seca-águas.

\section{Agradecimentos}

Ao CNPq (Conselho Nacional de Desenvolvimento Científico e Tecnológico) pela concessão da bolsa de Pós-Doutorado à primeira autora.

\section{Referências}

BARBOSA, A. M.; VALADARES, R. F. D.; VALADARES FILHO, S. C.; PINA, D. S.; DETMANN, E.; LEÃO, M. I. Endogenous fraction and urinary recovery of purine derivatives obtained by different methods in Nellore cattle. Journal of Animal Science, Champaign, v. 89, n. 2 , p. 510-519, 2011.

CHEN, X. B.; GOMES, M. J. Estimation of microbial protein supply to sheep and cattle basid on urinary excretion of purine derivatives-an overview of the technical details. Ocasional publication. Buchsburnd, Aberdeen: Ed. Rowett Research Institute, 1992. 21 p.

COUTO, V. R.M.; PAULINO, M. F.; DETMANN, E.; VALADARES FILHO, S. C.; SALES, M. F. L.; BARROS, L. V.; PORTO, M. O.; VALENTE, E. E. L. Energy sources and supplementation levels for beef heifers raised during the dry season. Revista Brasileira de Zootecnia, Viçosa, v. 39, n. 11 , p. 2494-2501, 2010. 
DETMANN, E.; PAULINO, M. F.; VALADARES FILHO, S. C. Avaliação nutricional de alimentos ou dietas? Uma abordagem conceitual. In: SYMPOSIUM OF BEEF CATTLE PRODUCTION, 6., 2008, Viçosa. Proceedings... Viçosa: UFV, Departamento de Zootecnia, 2008. p. 21-52.

Otimização do uso de recursos forrageiros basais. In: SYMPOSIUM OF BEEF CATTLE PRODUCTION, 7., 2010, Viçosa. Proceedings... Viçosa: UFV, Departamento de Zootecnia, 2010. p. 191-240.

DETMANN, E.; PAULINO, M. F.; ZERVOUDAKIS, J. T.; VALADARES FILHO, S. C.; EUCLIDES, R. F.; LANA, R. P.; QUEIRÓZ, D. S. Cromo e indicadores internos na determinação do consumo de novilhos mestiços, suplementados, a pasto. Revista Brasileira de Zootecnia, Viçosa, v. 30, n. 5, p. 1600-1609, 2001.

FIGUEIRAS, J. F.; DETMANN, E.; PAULINO, M. F.; VALENTE, T. N. P.; VALADARES FILHO, S. C.; LAZZARINI, I. Intake and digestibility in cattle under grazing supplemented with nitrogenous compounds during dry season. Revista Brasileira de Zootecnia, Viçosa, v. 39, n. 6, p. 1303-1312, 2010.

HALL, M. B.; AKINYODE, A. Cottonseed hulls: working with with a novel fiber source. In: ANNUAL FLORIDA RUMINANT NUTRITION SYMPOSIUM, 11., 2000, Gainesville. Proceedings... Gainesville: University of Florida, 2000. p. 179-186.

LAZZARINI, I.; DETMANN, E.; SAMPAIO, C. B.; PAULINO, M. F.; VALADARES FILHO, S. C.; SOUZA, M. A.; OLIVEIRA, F. A. Intake and digestibility in cattle fed low-quality tropical forage and supplemented with nitrogenous compounds. Revista Brasileira de Zootecnia, Viçosa, v. 38, n. 10, p. 20212030, 2009.

MERTENS, D. R. Gravimetric determination of amylase-treated neutral detergent fiber in feeds with refluxing in beaker or crucibles: collaborative study. Journal of AOAC International, Gaithersburg, v. 85, n. 6, p. 1217-1240, 2002.

MORAES, E. H. B. K.; PAULINO, M. F.; MORAES, K. A. K.; VALADARES FILHO, S. C.; ZERVOUDAKIS, J. T.; DETMANN, E. Uréia em suplementos protéicoenergéticos para bovinos de corte durante o período da seca: características nutricionais e ruminais. Revista Brasileira de Zootecnia, Viçosa, v. 38, n. 4, p. 770-777, 2009.

MORAES, E. H. B. K.; PAULINO, M. F.; VALADARES FILHO, S. C.; MORAES, K. A. K.; DETMANN, E.; SOUZA, M. G. Avaliação nutricional de estratégias de suplementação para bovinos de corte durante a estação seca. Revista Brasileira de Zootecnia, Viçosa, v. 39, n. 3, p. 608-616, 2010.

PAULINO, M. F.; DETMANN, E.; VALADARES FILHO, S. C. Bovinocultura funcional nos tópicos. In: SYMPOSIUM OF BEEF CATTLE PRODUCTION, 6., 2008, Viçosa. Proceedings... Viçosa: UFV, Departamento de Zootecnia, 2008. p. 275-305.

PAULINO, M. F.; FIGUEIREDO, D. M.; MORAES, E. H. B. K.; PORTO, M. O.; SALES, M. F. S.; ACEDO, T. S.; VILLELA, S. D. J.;VALADARES FILHO, S. C. Suplementação de bovinos em pastagens: uma visão sistêmica. In: SYMPOSIUM OF BEEF CATTLE PRODUCTION, 4., 2004, Viçosa. Proceedings... Viçosa: UFV, Departamento de Zootecnia, 2004. p. 93-139.

POPPI, D. P.; MCLENNAN, S. R. Protein and energy utilization by ruminants at pasture. 1995. Journal of Animal Science, Champaign, v. 73, n. 1, p. 278-290, 1995.

SAMPAIO, C. B.; DETMANN, E.; LAZZARINI, I.; SOUZA, M. A.; PAULINO, M. F.; VALADARES FILHO, S. C. Rumen dynamics of neutral detergent fiber in cattle fed low-quality tropical forage and supplemented with nitrogenous compounds. Revista Brasileira de Zootecnia, Viçosa, v. 38, n. 3, p. 560-569, 2009.

SAMPAIO, C. B.; DETMANN, E.; PAULINO, M. F.;.VALADARES FILHO, S. C.; SOUZA, M. A. de; LAZZARINI, I.; PAULINO, P. V. R.; QUEIROZ, A. C. de. Intake and digestibility in cattle fed low-quality tropical forage and supplemented with nitrogenous compounds. Tropical Animal Health and Production, v. 42, n. 7, p. 1471-1479, 2010.

SILVA, D. J.; QUEIROZ, A. C. Análise de alimentos: métodos químicos e biológicos. 3. ed. Viçosa: UFV, Imp. Univ., 2002. 165 p.

SILVA, L. F. C.; VALADARES FILHO, S. C.; CHIZZOTTI, M. L.; ROTTA, P. P.; PRADOS, L. F.; VALADARES, R. F.; BRAGA, J. M. S. Creatinine excretion and relationship with body weight of Nellore cattle. Revista Brasileira de Zootecnia, Viçosa, v. 41, n. 3, p. 807-810, 2012.

TITGEMEYER, E. C.; ARMENDARIZ, C. K.; BINDEL, D. J.; GREENWOOD, R. H.; LOEST, C. A. Evaluation of titanium dioxide as a digestibility marker for cattle. Journal of Animal Science, Champaign, v. 79, n. 4, p. 1059-1063, 2001.

VALADARES, R. F. D.; GONÇALVES, L. C.; RODRIGUEZ, N. M.; VALADARES FILHO, S. C.; SILVA, J. F. C. Níveis de proteína em dietas de bovinos. 2. Consumo, digestibilidade e balanço de compostos nitrogenados. Revista Brasileira de Zootecnia, Viçosa, v. 26, n. 6, p. 1259-1263, 1997. 
VALENTE, É. E. L.; PAULINO, M. F.; DETMANN, E.; VALADARES FILHO, S. C.; BARROS, L. V.; ACEDO, T. S.; COUTO, V. R. M.; LOPES, S. A. Levels of multiple supplements or nitrogen salt for beef heifers in pasture during the dry season. Revista Brasileira de Zootecnia, Viçosa, v. 40, n. 9, p. 2011-2019, 2011a. 2011a.

VALENTE, T. N. P.; DETMANN, E.; QUEIROZ, A. C.; VALADARES FILHO, S. C.; GOMES, D. I.; FILGUEIRAS, J. F. Evaluation of rumen degradation profiles of forages using bags made from different textiles. Revista Brasileira de Zootecnia, Viçosa, v. 40, n. 11, p. 2565-2573, 2011b. 2011 b.
VAN SOEST, P. J. Nutritional ecology of the ruminant. 2. ed. Ithaca: Cornell University Press, 1994. 476 p.

VAN SOEST, P. J.; ROBERTSON, J. B. Analysis of forages and fibrous foods. Ithaca: Cornell University, 1985. $202 \mathrm{p}$.

WILLIANS, C. H.; DAVID, D. J.; IISMA, O. The determination of chromic oxide in faeces samples by atomic absorption spectrophotometry. Journal of Agricultural Science, Cambridge, v. 59, n. 3, p. 381-385, 1962. 